\title{
Antithrombotic Strategy in Cerebral Venous Thrombosis: Differences Between Neurologist and Hematologist Respondents in a Canadian Survey
}

\author{
Thalia S. Field, Marie-Christine Camden, Sohaila Al-Shimemeri, Gary Lui, Agnes Y.Y. Lee
}

\begin{abstract}
Patterns of practice for management of cerebral venous thrombosis in Canada are unknown. We surveyed Canadian neurologists and hematologists regarding anticoagulation in cerebral venous thrombosis. The response rate was $28 \%$, with 27 neurologists and 20 hematologists responding. We found that choice of first-line initial anticoagulation differed significantly between neurologists and hematologists, with $89 \%$ of neurologists favouring unfractionated heparin and hematologists' preference split between unfractionated heparin (50\%) and low-molecular-weight heparin (50\%). Differences in patterns of practice likely reflect clinical equipoise.

RÉSUMÉ: Stratégie antithrombotique dans le traitement de la thrombose veineuse cérébrale : différences entre les neurologues et les hématologues qui ont répondu à une enquête canadienne. Les modes de pratique concernant le traitement de la thrombose veineuse cérébrale au Canada ne sont pas connus. Nous avons procédé à une enquête auprès des neurologues et des hématologues canadiens concernant l'anticoagulation dans le traitement de la thrombose veineuse cérébrale. Vingt-sept neurologues et 20 hématologues ont répondu à l'enquête, soit $28 \%$ des spécialistes pressentis. Nous avons constaté que le choix de l'anticoagulant comme traitement initial de première ligne était significativement différent entre les neurologues et les hématologues : 89\% des neurologues préféraient administrer de l'héparine non fractionnée alors que 50\% des hématologues préféraient administrer de l'héparine non fractionnée et $50 \%$ préféraient administrer de l'héparine de faible poids moléculaire. Les différences entre ces modes de pratique reflètent vraisemblablement leur équilibre clinique.
\end{abstract}

Keywords: Cerebral Venous Thrombosis, Anticoagulation, Venous Thromboembolism, Direct Oral Anticoagulants, Novel Oral Anticoagulants, Treatment

doi:10.1017/cjn.2016.297

Can J Neurol Sci. 2017; 44: 116-119

Cerebral venous thrombosis (CVT) refers to thrombosis of the draining dural venous sinuses and deep and superficial cerebral veins. It is a rare cause of stroke, affecting approximately $1 / 100,000$ annually. ${ }^{1,2}$ Anticoagulation is the mainstay of treatment, although evidence for its efficacy has never been confirmed in large randomized trials, and optimal choice of anticoagulant at initial presentation and for maintenance therapy is unknown. ${ }^{3,4}$ Knowledge of current national patterns of practice with regards to management of CVT is unknown. We surveyed Canadian neurologists and hematologists regarding their use of anticoagulation for treatment of CVT.

\section{Methods}

The study was approved by the Clinical Research Ethics Board at the University of British Columbia. Participants were recruited from two national email lists: the Canadian Stroke Consortium (CSC), which has 125 physician members involved in treatment of stroke, mostly neurologists, and Thrombosis Canada (TC), which has 70 physician members, mostly hematologists, involved in treatment of thrombosis. The survey consisted of 15 questions regarding individual patterns of practice for initial and maintenance anticoagulation for CVT, estimated annual case volume at the respondent's center, and demographic information. Minor specialty-specific modifications were made for the CSC and TC surveys, and the survey was available to respondents in either
English or French (see Supplementary data). Responses were anonymized. Participation in a draw to win a $\$ 50$ Amazon gift card was offered as an incentive. The survey remained open for 3 months, and one reminder was sent to each list after 6 weeks.

Individual participant responses were exported from the survey's web interface (FluidSurveys University platform) into SPSS 23 (Armonk, NY) and analyzed using descriptive statistics, chi-square, and Wilcoxon rank-sum tests as applicable.

\section{ReSUlts}

Twenty-nine of $113(25.6 \%)$ physicians on the mailing list for the CSC and 22/70 (31.4\%) physicians from the TC list participated. Unless respondents on the CSC and TC lists identified themselves as nonneurologists or nonhematologists $(n=4)$, we assumed that these respondents were specialists in those areas (neurologists, $\mathrm{n}=27$; hematologists, $\mathrm{n}=20$ ). The majority of

From the Djavad Mowafaghian Centre for Brain Health, Division of Neurology, Department of Medicine, University of British Columbia (TSF, SA-S, GL); Division de Neurologie, Department de médecine, Universitaire de Quebec, Quebec City, Canada (M-CC); Division of Hematology, Department of Medicine, University of British Columbia (AYYL).

Received March 15, 2016. Final Revisions Submitted July 3, 2016. Date of ACCEPTANCE July 8, 2016.

Correspondence to: Thalia Field, Division of Hematology, Department of Medicine, University of British Columbia, V6T 2B5. Email: thalia.field@ubc.ca 


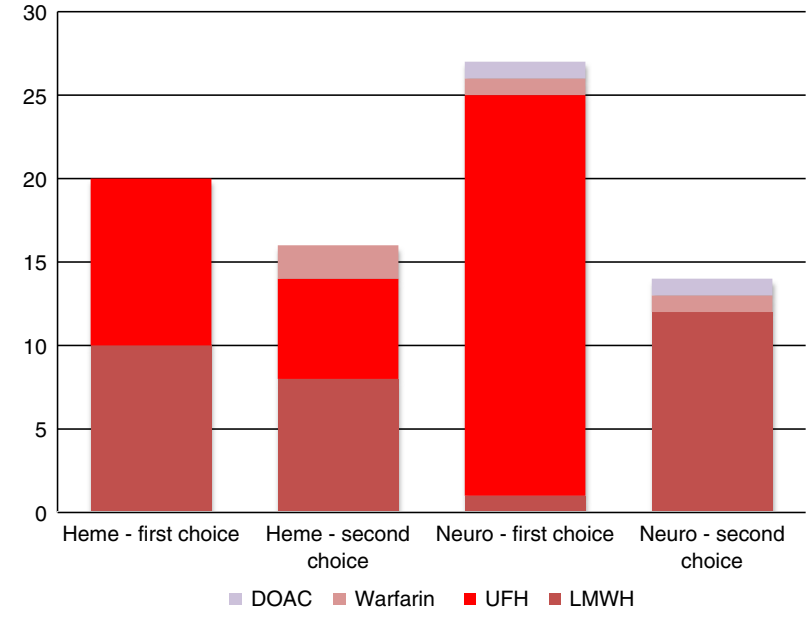

Figure 1: First- and second-choice anticoagulants for initial treatment of CVT by speciality.

respondents devoted more than $50 \%$ of their practice to stroke neurology $(81.5 \%$ of neurologists) or thrombosis $(60.0 \%$ of hematologists) (Supplementary Table 1).

For initial anticoagulation in CVT, neurologists preferred unfractionated heparin as a first-line agent (89\%), compared with $50 \%$ of hematologists $(\mathrm{p}=0.002)$. Low-molecular-weight heparin (LMWH) was also first-line for 50\% of hematologists (Figure 1, Supplementary Table 1). For maintenance anticoagulation, warfarin was the first choice for neurologists and hematologists $(85.2 \%$ and $70.0 \%$, respectively). The majority $(57.1 \%)$ of neurologists reported that they would prescribe LMWH as a second choice for maintenance anticoagulation; $25 \%$ would use a direct oral anticoagulant. For hematologists, $53 \%$ chose LMWH and $16 \%$ direct oral anticoagulant as second-line anticoagulant (Figure 2). Factors cited as most frequently or consistently contributing to choice of anticoagulant in the acute and maintenance phase for both specialties were comorbidities, whether the patient was pregnant or breastfeeding, and, for the maintenance phase, patient preference (Tables 1 and 2).

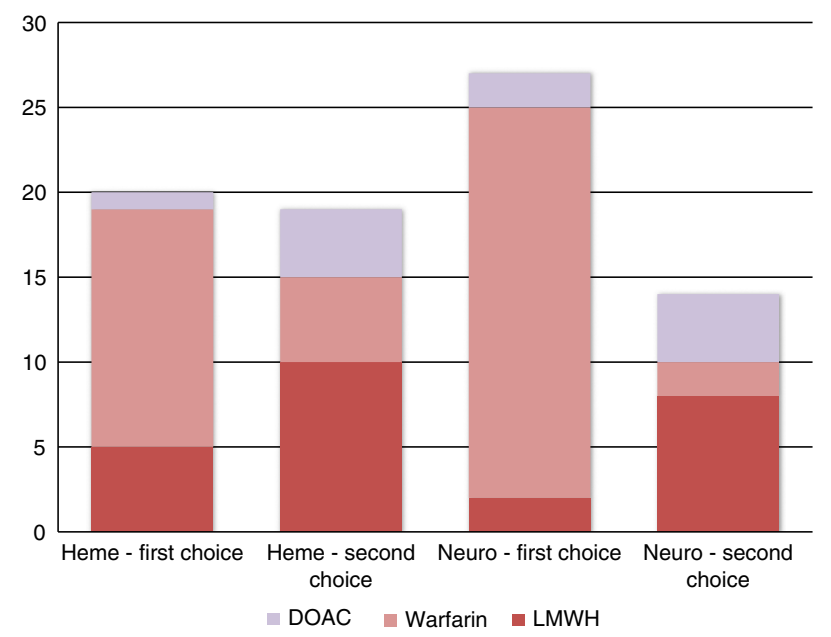

Figure 2: First- and second-choice anticoagulants for maintenance treatment of CVT by speciality.

\section{Table 1: Factors affecting choice of initial anticoagulant}

\begin{tabular}{|c|c|c|c|c|c|}
\hline $\begin{array}{l}\text { Considerations } \\
\text { with initial } \\
\text { anticoagulant }\end{array}$ & $\begin{array}{l}\text { Never, } \mathbf{n} \\
(\%)\end{array}$ & $\begin{array}{l}\text { Rarely, } \\
\text { n }(\%)\end{array}$ & $\begin{array}{c}\text { Frequently, } \\
\text { n (\%) }\end{array}$ & $\begin{array}{c}\text { Consistently, } \\
\text { n (\%) }\end{array}$ & $\begin{array}{c}\text { Missing } \\
\text { response }\end{array}$ \\
\hline \multicolumn{6}{|l|}{ Patient age } \\
\hline Neurologist & $13(50.0)$ & $10(38.5)$ & $3(11.5)$ & $0(0)$ & 1 \\
\hline Hematologist & $11(57.9)$ & $6(31.6)$ & $2(10.5)$ & $0(0)$ & 1 \\
\hline \multicolumn{6}{|l|}{ Comorbidities } \\
\hline Neurologist & $5(19.2)$ & $7(26.9)$ & $11(42.3)$ & $3(11.5)$ & 1 \\
\hline Hematologist & $6(31.6)$ & $4(21.1)$ & $5(26.3)$ & $4(21.1)$ & 1 \\
\hline \multicolumn{6}{|l|}{$\begin{array}{l}\text { Pregnant/ } \\
\text { breastfeeding }\end{array}$} \\
\hline Neurologist & $1(3.8)$ & $11(42.3)$ & $5(19.2)$ & $9(47.3)$ & 1 \\
\hline Hematologist & $7(36.8)$ & $2(10.5)$ & $5(26.3)$ & $5(26.3)$ & 1 \\
\hline \multicolumn{6}{|l|}{$\begin{array}{l}\text { Venous } \\
\text { hemorrhage }\end{array}$} \\
\hline Neurologist & $6(23.1)$ & $13(50.0)$ & $3(11.5)$ & $4(15.4)$ & 1 \\
\hline Hematologist & $4(20.0)$ & $7(35.0)$ & $6(30.0)$ & $3(15.0)$ & 0 \\
\hline \multicolumn{6}{|l|}{ Venous infarct } \\
\hline Neurologist & $6(23.1)$ & $13(50.0)$ & $3(11.5)$ & $4(15.4)$ & 1 \\
\hline Hematologist & $4(20.0)$ & $7(35.0)$ & $6(30.0)$ & $3(15.0)$ & 0 \\
\hline \multicolumn{6}{|l|}{$\begin{array}{l}\text { Thrombus } \\
\text { burden }\end{array}$} \\
\hline Neurologist & $7(26.9)$ & $12(46.2)$ & $6(23.1)$ & $1(3.7)$ & 1 \\
\hline Hematologist & $5(26.3)$ & $5(26.3)$ & $6(31.6)$ & $3(15.8)$ & 1 \\
\hline \multicolumn{6}{|l|}{$\begin{array}{l}\text { Patient } \\
\text { preference }\end{array}$} \\
\hline Neurologist & $6(24.0)$ & $11(44.0)$ & $7(28.0)$ & $1(4.0)$ & 2 \\
\hline Hematologist & $6(31.6)$ & $7(36.8)$ & $3(15.8)$ & $3(15.8)$ & 1 \\
\hline \multicolumn{6}{|l|}{ Medico-legal } \\
\hline Neurologist & $14(51.9)$ & $11(40.7)$ & $1(3.7)$ & $0(0)$ & 1 \\
\hline Hematologist & $12(63.2)$ & $4(21.1)$ & $0(0)$ & $3(15.8)$ & 1 \\
\hline \multicolumn{6}{|l|}{$\begin{array}{r}\text { Ability to } \\
\text { swallow }\end{array}$} \\
\hline Neurologist & $5(19.2)$ & $15(57.7)$ & $5(19.2)$ & $1(3.8)$ & 1 \\
\hline Hematologist & $7(41.2)$ & $5(29.4)$ & $4(23.5)$ & $1(5.9)$ & 3 \\
\hline \multicolumn{6}{|l|}{$\begin{array}{l}\text { Neurological } \\
\text { disability }\end{array}$} \\
\hline Neurologist & $6(23.1)$ & $11(42.3)$ & $8(30.8)$ & $1(3.8)$ & 1 \\
\hline Hematologist & $6(30.0)$ & $4(20.0)$ & $4(20.0)$ & $6(30.0)$ & 0 \\
\hline
\end{tabular}

The majority of neurologists routinely chose a duration of anticoagulation of less than 1 year (6 months or less, $44.4 \%$; $>6$ months but $<1$ year, $25.9 \%$ ); a minority made their decisions based on repeat vascular imaging (14.8\%) or hematology consultation $(14.8 \%)$. The majority of hematologists also chose a treatment period of less than 1 year ( $\leq 6$ months, $50 \% ;>6$ months but $<1$ year, 30\%). A minority of hematologists chose to treat for longer than 1 year (20\%), and none chose repeat vascular imaging to determine duration of treatment (Table 3).

\section{DISCUSSION}

In this cohort, there are differences between neurologists and hematologists with regards to initial choice of anticoagulant in CVT. As many as $30 \%$ to $40 \%$ of patients with CVT present with venous hemorrhage on presentation, ${ }^{5,6}$ and it is possible that more complex presenting cases of CVT with concurrent venous 
Table 2: Factors affecting choice of maintenance anticoagulant

\begin{tabular}{|c|c|c|c|c|c|}
\hline Considerations & $\begin{array}{l}\text { Never, } \mathbf{n} \\
(\%)\end{array}$ & $\begin{array}{c}\text { Rarely, } \\
\text { n }(\%)\end{array}$ & $\begin{array}{c}\text { Frequently, } \\
\text { n (\%) }\end{array}$ & $\begin{array}{c}\text { Consistently, } \\
\text { n (\%) }\end{array}$ & $\begin{array}{l}\text { Missing } \\
\text { response }\end{array}$ \\
\hline \multicolumn{6}{|l|}{ Comorbidities } \\
\hline Neurologist & $1(3.8)$ & $13(48.1)$ & $8(29.6)$ & $3(11.1)$ & 2 \\
\hline Hematologist & $1(5.0)$ & $8(40.0)$ & $6(30.0)$ & $5(25.0)$ & 0 \\
\hline \multicolumn{6}{|l|}{$\begin{array}{l}\text { Pregnant/ } \\
\text { breastfeeding }\end{array}$} \\
\hline Neurologist & $0(0)$ & $13(50.0)$ & $5(18.5)$ & $8(30.8)$ & 1 \\
\hline Hematologist & $0(0)$ & $6(30.0)$ & $4(20.0)$ & $10(50.0)$ & 0 \\
\hline \multicolumn{6}{|l|}{$\begin{array}{c}\text { Thrombus } \\
\text { burden }\end{array}$} \\
\hline Neurologist & $9(34.6)$ & $11(42.3)$ & $3(11.5)$ & $3(11.5)$ & 1 \\
\hline Hematologist & $5(25.0)$ & $6(30.0)$ & $7(35.0)$ & $2(10.0)$ & 0 \\
\hline \multicolumn{6}{|l|}{$\begin{array}{l}\text { Patient } \\
\text { preference }\end{array}$} \\
\hline Neurologist & $3(11.1)$ & $14(51.9)$ & $8(29.6)$ & $2(7.4)$ & 0 \\
\hline Hematologist & $3(15.8)$ & $5(26.3)$ & $7(36.8)$ & $4(21.1)$ & 1 \\
\hline \multicolumn{6}{|l|}{ Medico-legal } \\
\hline Neurologist & $12(46.2)$ & $12(46.2)$ & $2(7.7)$ & $0(0.0)$ & 1 \\
\hline Hematologist & $13(68.4)$ & $3(15.8)$ & $1(5.3)$ & $2(10.5)$ & 1 \\
\hline \multicolumn{6}{|l|}{$\begin{array}{c}\text { Neurological } \\
\text { disability }\end{array}$} \\
\hline Neurologist & $9(34.6)$ & $12(46.2)$ & $5(19.2)$ & $0(0)$ & 1 \\
\hline Hematologist & $5(26.3)$ & $7(36.8)$ & $4(21.1)$ & $3(15.8)$ & 1 \\
\hline
\end{tabular}

infarction, hemorrhage, or seizure may present to neurologists as compared with hematologists. Thus, an initial preference for unfractionated heparin may reflect a desire for a reversible agent with a short half-life in the event of bleeding complications in an unstable patient, though clinically relevant bleeding remains a rare complication in patients with CVT and venous hemorrhage. ${ }^{1,7-9}$ However, most neurologists and hematologists endorsed that thrombus burden and presence of venous haemorrhage "never" or "rarely" affected their choice of anticoagulant. Specialty-specific thought leaders as well as local patterns of practice may also influence choice of anticoagulant, although we did not have sufficient representation from a number of physicians from the same centres to examine this latter possibility.

Fewer than half of neurologists provided a second choice for maintenance anticoagulation. Whether this reflects a strong preference for warfarin alone, a lack of experience with alternative anticoagulants in a rare condition, or neurology involvement primarily in the acute treatment phase only, is uncertain.

Table 3: Duration of anticoagulation by specialty

\begin{tabular}{l|c|c|c}
\hline Duration of anticoagulation & $\begin{array}{c}\text { Neurologists, } \\
\mathbf{n}(\mathbf{\%}) \\
\mathbf{N}=\mathbf{2 7}\end{array}$ & $\begin{array}{c}\text { Hematologists, } \\
\mathbf{n}(\mathbf{\%}) \\
\mathbf{N}=\mathbf{2 0}\end{array}$ & $\mathbf{p}$ \\
\hline 6 months or less & $12(44.4)$ & $10(50.0)$ & 0.022 \\
\hline$>6$ months but <1 year & $7(25.9)$ & $6(30.0)$ & \\
\hline$>1$ year & $0(0)$ & $4(20.0)$ & \\
\hline $\begin{array}{l}\text { Depends on the results of repeat vascular } \\
\text { imaging }\end{array}$ & $4(14.8)$ & $0(0)$ & \\
\hline $\begin{array}{c}\text { As per hematologist's recommendation } \\
\text { (CSC list only) }\end{array}$ & $4(14.8)$ & $0(0)$ & \\
\hline
\end{tabular}

Most neurologists and hematologists treated patients with anticoagulation for less than a year, which is consistent with contemporary management guidelines. ${ }^{3,4}$ Potential rationales for prolonged treatment, such as results of thrombophilia testing, were not included in our survey. A minority (14.8\%) of neurologists used repeat vascular imaging, presumably assessing for recanalization, to guide their decision-making with regards to duration of anticoagulation.

Our results should be extrapolated with caution. Limitations to this study include inherent selection biases in those who voluntarily participated in the survey, as well the means through which the survey was distributed and potential biases in the survey's construction. The website for the Royal College of Physicians and Surgeons of Canada lists 971 neurologists (adult and pediatric) and 550 hematologists practicing in Canada. Our survey respondents thus represent a small proportion of these specialists; therefore, reported practice patterns may not apply to Canadian CVT patients in general. The overwhelming majority of respondents (all but two) were from academic centres and responses may not reflect patterns of practice in the community. Our $28 \%$ response rate is consistent with other contemporary web-based physician surveys not using unconditional incentives. ${ }^{10}$ Given that surveys were released to both email lists simultaneously, we assume that there was no double-counting from respondents who could have subscribed to both email lists and replied to the survey twice, though, given that responses were anonymized, we do not know this for certain.

\section{Conclusion}

Reported patterns of practice with regards to choice of anticoagulant for CVT are heterogeneous and differ significantly in the acute phase between neurologists and hematologists. This reflects clinical equipoise regarding optimal antithrombotic strategy for CVT.

\section{ACKNOWLEDGEMENTS AND FUNDING}

The authors are grateful to Karen Earl at the Canadian Stroke Consortium and Nicola Banks and Megan Connolly at Thrombosis Canada for their assistance in distributing the survey; Drs. Ken Butcher, Michael Hill, Eric Smith, and Michel Shamy for their advice on the survey's content and distribution; Mr. Franco Cermeno for technical assistance; and Dr. Madeleine Sharp for translating an earlier iteration of the survey, and to all participants for their assistance. TSF is supported by a Mentored Clinician Scientist Award from the Vancouver Coastal Health Research Institute.

\section{Disclosures}

TSF has the following disclosures: Boehringer Ingleheim Canada: research and research grant; Bayer Canada: speaker bureau, honoraria; and Bayer Canada: advisory board, honoraria. AYYL has the following disclosures: Bayer Canada: consultant, honoraria, and consulting fees; Leo Pharma: consultant, honoraria, and consulting fees; Pfizer: consultant, honoraria, and consulting fees; BMS: research support, research grant. MCC has the following disclosures: BMS, consultant/advisor, consulting fees; BMS: speaker, honoraria; Bayer: consultant/advisor, consulting fees; Bayer: speaker, honoraria; Pfizer: consultant/ advisor, consulting fees; Pfizer: speaker, honoraria; Boehringer: 
speaker, honoraria. SA-S and GL do not have anything to disclose.

\section{Statement of Authorship}

TSF drafted the survey and the manuscript. MCC codrafted the survey and provided the French translation. SA-S and GL participated in data analysis and interpretation. AYYL revised the survey and the content of the manuscript.

\section{SUPPLEMENTARY MATERIAL}

To view supplementary material for this article, please visit http://dx.doi.org/10.1017/cjn.2016.297

\section{REFERENCES}

1. Ferro JM, Correia M, Pontes C, Baptista MV, Pita F, Cerebral Venous Thrombosis Portuguese Collaborative Study Group. Cerebral vein and dural sinus thrombosis in Portugal: 1980-1998. Cerebrovasc Dis. 2001;11:177-82.

2. Borhani Haghighi A, Edgell RC, Cruz-Flores S, et al. Mortality of cerebral venous-sinus thrombosis in a large national sample. Stroke. 2012;43:262-4.
3. Saposnik G, Barinagarrementeria F, Brown RD, Jr., et al. Diagnosis and management of cerebral venous thrombosis: a statement for healthcare professionals from the American Heart Association/ American Stroke Association. Stroke. 2011;42:1158-92.

4. Einhaupl K, Stam J, Bousser MG, et al. EFNS guideline on the treatment of cerebral venous and sinus thrombosis in adult patients. Eur J Neurol. 2010;17:1229-35.

5. Girot M, Ferro JM, Canhao P, et al. Predictors of outcome in patients with cerebral venous thrombosis and intracerebral hemorrhage. Stroke. 2007;38:337-42.

6. Wasay M, Bakshi R, Bobustuc G, et al. Cerebral venous thrombosis: analysis of a multicenter cohort from the United States. J Stroke Cerebrovasc Dis. 2008;1:49-54.

7. Bousser MG, Chiras J, Bories J, Castaigne P. Cerebral venous thrombosis-a review of 38 cases. Stroke. 1985;16:199-213.

8. Brucker AB, Vollert-Rogenhofer H, Wagner M, et al. Heparin treatment in acute cerebral sinus venous thrombosis: a retrospective clinical and MR analysis of 42 cases. Cerebrovasc Dis. 1998;8:331-7.

9. Wingerchuk DM, Wijdicks EF, Fulgham JR. Cerebral venous thrombosis complicated by hemorrhagic infarction: factors affecting the initiation and safety of anticoagulation. Cerebrovasc Dis. 1998;8:25-30.

10. VanGeest JB, Johnson TP, Welch VL. Methodologies for improving response rates in surveys of physicians: a systematic review. Eval Health Prof. 2007;30:303-21. 